\title{
Application of Seismic Reservoir in Sedimentary Facies
}

\author{
Li Xin, Zhao Rumin, Yang Ting, Wang Beibei, Bai Bo \\ CNOOC Research Institute, Beijing100028,China \\ hunter2011@foxmail.com
}

Keywords: Seismic fault, Reservoir, Structural fault.

\begin{abstract}
Fracture system is main geological factor to control the formation and preservation of oil gas reservoir. And deepening the understandings to the formation and evolution of petroleum basin fracture are necessary for us to know the geological condition used for form the oil gas in petroleum basin and explore the control effects of fracture in regulations of oil gas distribution. According to 76 wells and 97 fracture points we combine the Dongying sag fracture systems in this article. The number of the faults that have been combined in this area is 15 in total. The faults are located at the northward and the westward in this area. These roughly can be divided into three groups according to its trend. Six strips are in east-west direction. And theses involved three main faults, namely number 7 , number 37 and number 46 . Two strips are in the direction from northwest to southeast. Seven strips are the direction from northeast to southwest. And these involved three mainfaults, namely number 16 , number 17 and number 40 .

Dongying sag is a secondary tectonic unit in Jiyang depression at Bohai gulf basin. And it is a depression basin with steep dip angle in the north limb and gentle in the south. The length from east to west is $90 \mathrm{~km}$, and the width from south to north is $65 \mathrm{~km}$. The south is Luxi uplift, the north is Chenjiazhuang uplift, the east is Qingtuozi uplift, and the west is Binxian uplift. It is the tertiary downfaulted basins of late Jurassic, which is surrounded by bulges and connects with other bulges, and after the tertiary of late Jurassic, it belongs to north China offshore depression basin.

Shengtuo oilfield is located at the middle of the secondary tectonic fracture zone, Tuozhuang, Shengli village,Yongan town of Dongying sag. It is tow anticline structure connected by saddles, which is located at the south side of Shengbei curviplanar fracture. Shengyi area is located at the westward of Shengtuo oilfield, and the structure is relatively simple. We take the number 7 fault as the border in northward of Shengyi area to connect with Tuo 15-Tuo 40 fault blocks. And this fault goes across big fault of Shengtuo oilfiel. The southward is alar part of anticline structure, and the stratum is pitching gradually. The eastward connects with the second section by saddles of Tuozhuang structure, and the westward is flank of the anticline.
\end{abstract}

\section{The Study of Seismic Fracture System}

Fracture system is main geological factor to control the formation and preservation of oil gas reservoir. And deepening the understandings to the formation and evolution of petroleum basin fracture are necessary for us to know the geological condition used for form the oil gas in petroleum basin and explore the control effects of fracture in regulations of oil gas distribution. According to 76 wells and 97 fracture points we combine the Dongying sag fracture systems in this article. The number of the faults that have been combined in this area is 15 in total. The faults 
are located at the northward and the westward in this area.These roughly can be divided into three groups according to its trend. Six strips are in east-west direction. And theses involved three main faults, namely number 7, number 37 and number 46. Two strips are in the direction from northwest to southeast. Seven strips are the direction from northeast to southwest. And these involved three mainfaults, namely number 16, number 17 and number 40 .

The features can be shown as follows.

Fault Number 7. Its trend is nearly eastwest direction, and the fault displacement is $100-300 \mathrm{~m}$, and the surface dip angle is about $48^{\circ}$, and the tendency is closing due north, and the stretch length inside this area is $+3.8 \mathrm{k}$. This fault is a regional large fault. It has formed during early phase of Shahejie formation. Dongying formation is its main growth stage. It obviously control the depositions of paleogene system, which has certain control effects to the enrichment of oil gas. Along with the direction at downthrow wall, there are a series of reserve traction structure. For instance, 4-6 sands group of the second section in Shengyi area.This fracture is north boundary fault of 4-6 sands group of the second section in Shengyi area.It is III grade fault.

Fault Number 16. Its trend is nearly eastwest direction. And the inclined direction is south. The stretch length inside the area is about $1.2 \mathrm{~km}$. The fault dip angle is about $46^{\circ}$. It is IV grade fault.

Fault Number 17. Its trend is from northeast to southwest. And the inclined direction is southeast. The fault displacement in northeast is larger than the fault displacement in southwest. The stretch length inside the area is about $1.6 \mathrm{~km}$. The fault dip angle is about $47^{\circ}$. It is IV grade fault.

Shahe formation sedimentary period in the plaeogene system, the mountains were rising, the lakes were shrinking, and the lake water was less. Because the climate is moist, the rainfall is sufficient, and the rivers are abundant. The resources in the uplifts are abundant, and enormous chippings carried by river have formed the deposition of delta facies after being a part of lake.With the development and enlargement of deltas, the rivers have met with each other, and the deltas have connected with each other and the complex delta has been formed gradually in this condition so that it has multi-resource and multi-river system. In this period, the differences exsit between the south and the north. The early period of Dongying sag is the depositions of plains and bogs. Most of lake water withdraws in the late period. The main part is the depositions of river facies.

\section{The Study of Deposition Feature}

Rock Facies Marks. Deposition of 4-6 sands group of the second upper sub section in Shengyi area evidently has the reverse rhythm depositional characteristics of delta front. And it has positive rhythm depositions of branch river channels in depositions of delta plain (involved 6-5 sands group ) as well as mud carbon depositions in bog condition (involved 4 sands group ).

Mudstone Facies. The mudstones in Shengyi area are all ash black. There are the underwater depositions that were enriched with organic materials and certain carbonaceous shale depositions in bog condition.

Sandstone Facies. The 4-6sands group are all middle sandstone and fine sandstone. The shale content is low. The separation is well. The quartz is the main ingredients of terrigenous clastic. The second is feldspar and rock debris. And one quartz equals to one and a half feldspar.

Ancient Biology Marks. The fossil content of ancie nt biology in 4-6 sands group of the second section is scarce, but it is good marks to the recognition of deposition conditions. Through observing rock heart and authenticating chip, the carbon debris and gastropod 
are main fossils of ancient biology. The plant carbon debris are shown in the form of many layers in 4-6 sands group of the second section. They are mainly stored in mudstones and muddy siltstone of delta leading edge and delta plain that is in delta deposition condition.Gastropods are mainly distributed at mudstones of delta plain that is in delta deposition condition.

Features of Depositional Structure. Depositional structure is an comprehensive reflection of hydrodynamic condition and deposition condition during deposition transport. It is the resume of deposition in depositional environment. It is main evidence to study the depositional condition of deposition.

Grading Analysis. We mainly analyze the grain size characteristics in the coring documents of 1-1 Jian 53 well through sieve analysis. We study the depositional condition through the probability accumulation curve and graph C-M.

(1) Probability Curve. 4 sands group. As shown in figure 1 below, the probability curve of 4 sands group has two kinds, namely two sections and three sections. Among them they are mainly two sections, and a few of them are three sections. Two sections mainly consist of jump component and suspension component. And the fine cut point is usually between 3 to $3.5 \varphi$. The jump component accounts for $80 \%$, and the suspension component accounts for $20 \%$. The maximum slope and the minimum slope are $75^{\circ}$ and $25^{\circ}$ respectively, generally between $60^{\circ}$ to $70^{\circ}$. Three sections mainly consist of jump component, rolling component and suspension component. The rolling component is less than $5 \%$, and mostly it is about $3 \%$. The suspension component accounts for $10 \%$ to $20 \%$. The rough cut point is about $2.5 \varphi$. The fine cut point is about $3.5 \varphi$. The slope is between $\underset{1-1-153(47-1)}{60^{\circ}}$ to $70^{\circ}$.

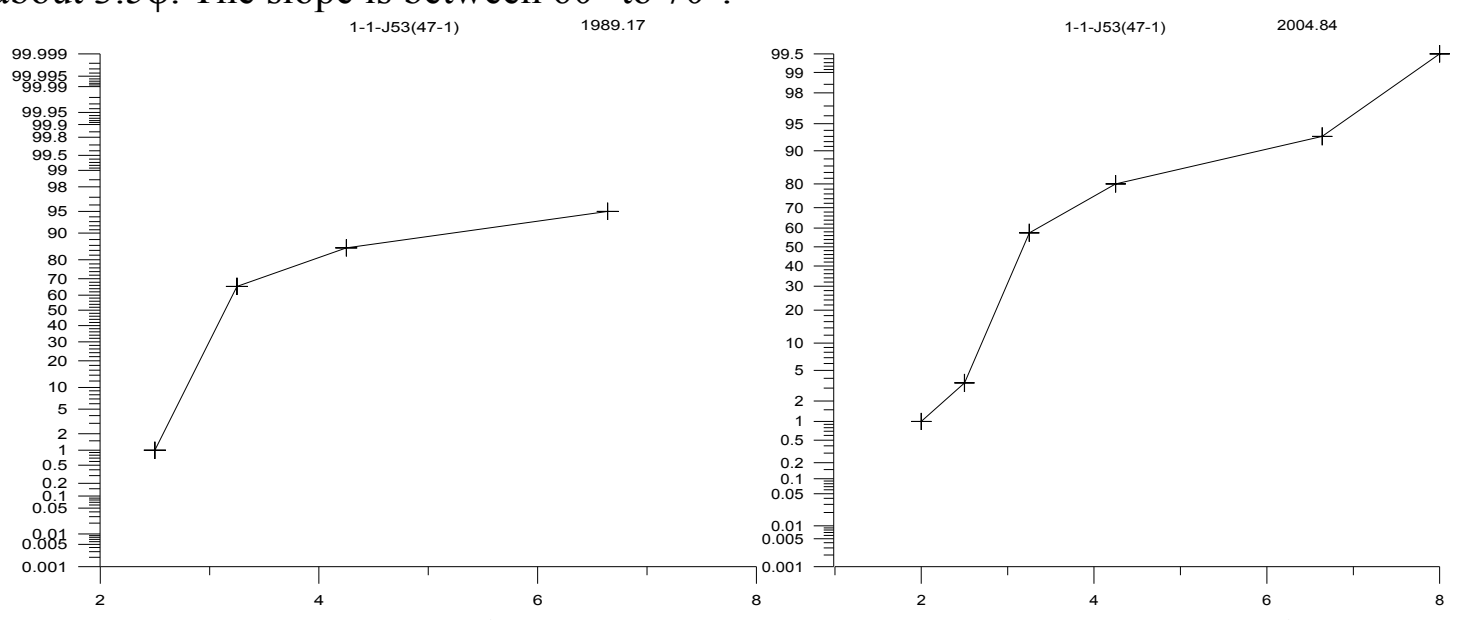

(a)Two sections

(b)Three sections

The probability curve graph of 1 1-1-J53 4 well in sands two section

5 sands group. As shown in figure 2 below, the probability curve of 4 sands group has two kinds, namely two section and one section. Among them they are mainly two sections. Two sections mainly consist of treaty component and suspension component. The fine cut point is usually about $3.5 \varphi$. The jump component accounts for about $75 \%$. The suspension component accounts for $10 \%$ to $20 \%$. The slope is usually about $60^{\circ}$. One section consists of rolling component, jump component and suspension component. The three components are hard for us to separate as a whole. The rough cut point and fine cut point are not obvious. The slope is smooth. It is usually about $40^{\circ}$. 


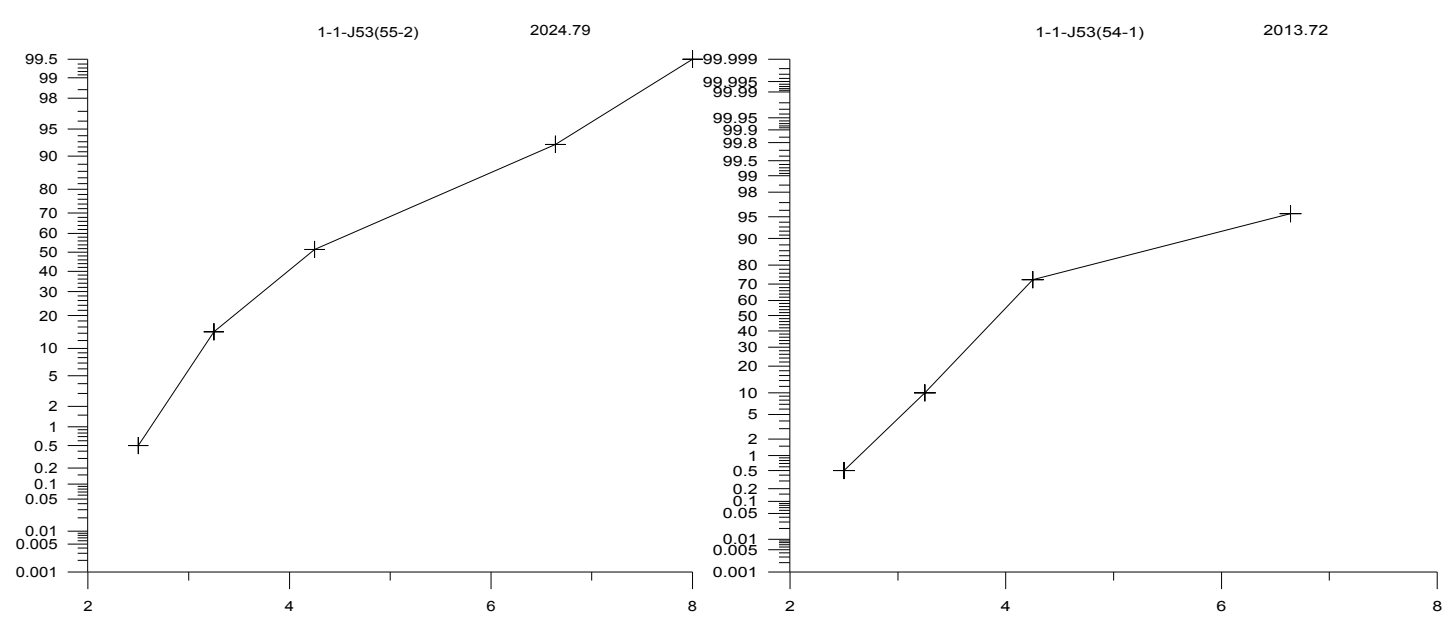

(a) One section

(b) Two sections

The probability curve graph of 1 1-1-J53 5 well sands in two section c.sands group 6

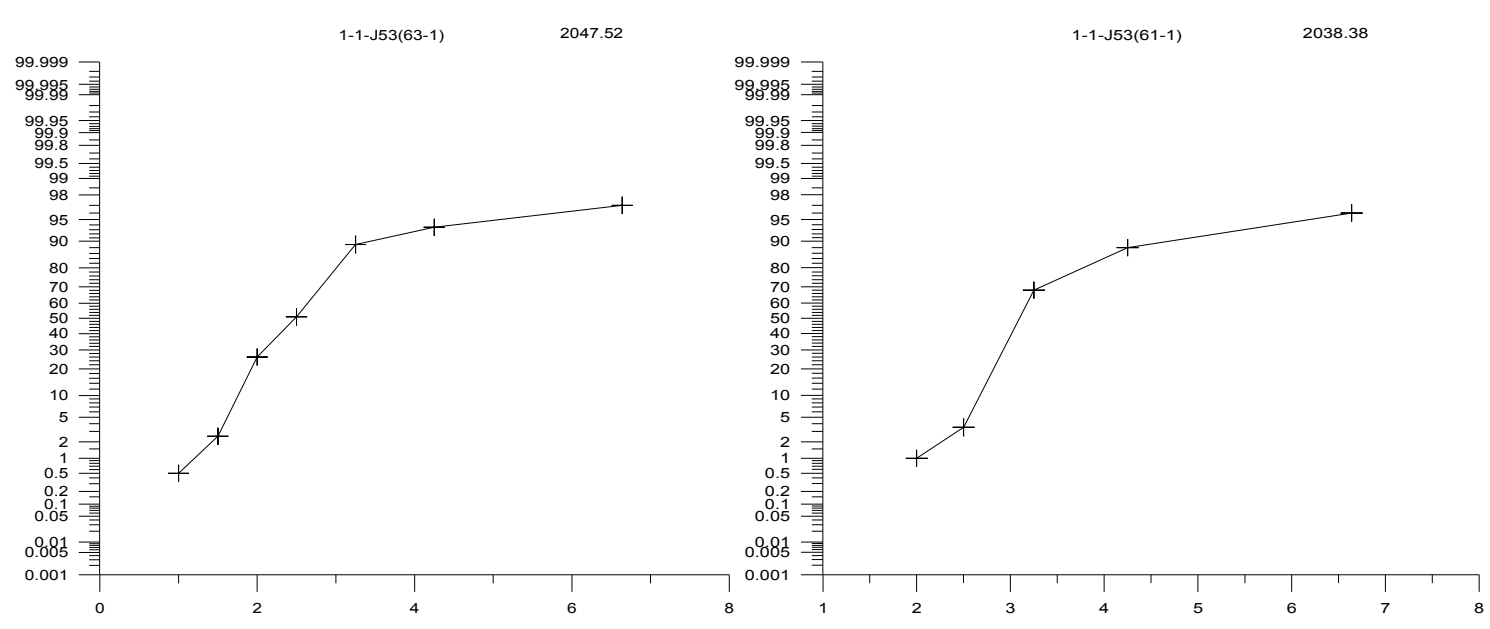

As shown in graph 3 above, the probability curve of 4 sands group has two kinds, namely two sections, three sections and one section. Among them they are mainly two sections. Two sections mainly consist of jump component and suspension component. The fine cut point is usually about $3.5 \varphi$. The jump component accounts for about $80 \%$. The suspension component accounts for $10 \%$ to $20 \%$. Mostly the slope is $65^{\circ}$. It is usually about $60^{\circ}$ to $70^{\circ}$. Three sections mainly consist of jump component, rolling component and suspension component. The rolling component is less than 10\%, and mostly it is about $5 \%$. The suspension component accounts for $10 \%$ to $20 \%$. The rough cut point is $1.5 \varphi$. The fine cut point is about $3 \varphi$. The slope is about $55^{\circ}$ to $65^{\circ}$. One section consists of rolling component, jump component and suspension component. They are hard to separate as a whole. The rough cut point and fine cut point are not obvious. The slope is smooth. It is usually about $40^{\circ}$ to $50^{\circ}$.

(2) Graph C-M. As shown is graph 4 below, graph C-M of 4 sands group mainly consists of QR section. Lack of OP section, the growth of PQ section and RS section are not well The graph $\mathrm{C}-\mathrm{M}$ of 5 sands group mainly consists of QR section. The graph C-M of 6 sands group mainly consists of PQ section. The main representative of PQ section is suspension transport. There are a few rolling transports. The change of value $\mathrm{C}$ is large, but the change of value $\mathrm{M}$ is little. $\mathrm{QR}$ section represents the grained suspension section. It generally grows in bottom of water body, and 
it is formed by eddy effect. The depositions mostly do not have rolling transports. The value $\mathrm{C}$ and value $\mathrm{M}$ are proportion relation. RS section represents the average suspension section. The depositions are silt and mud. The value $\mathrm{C}$ doesn't change basically.
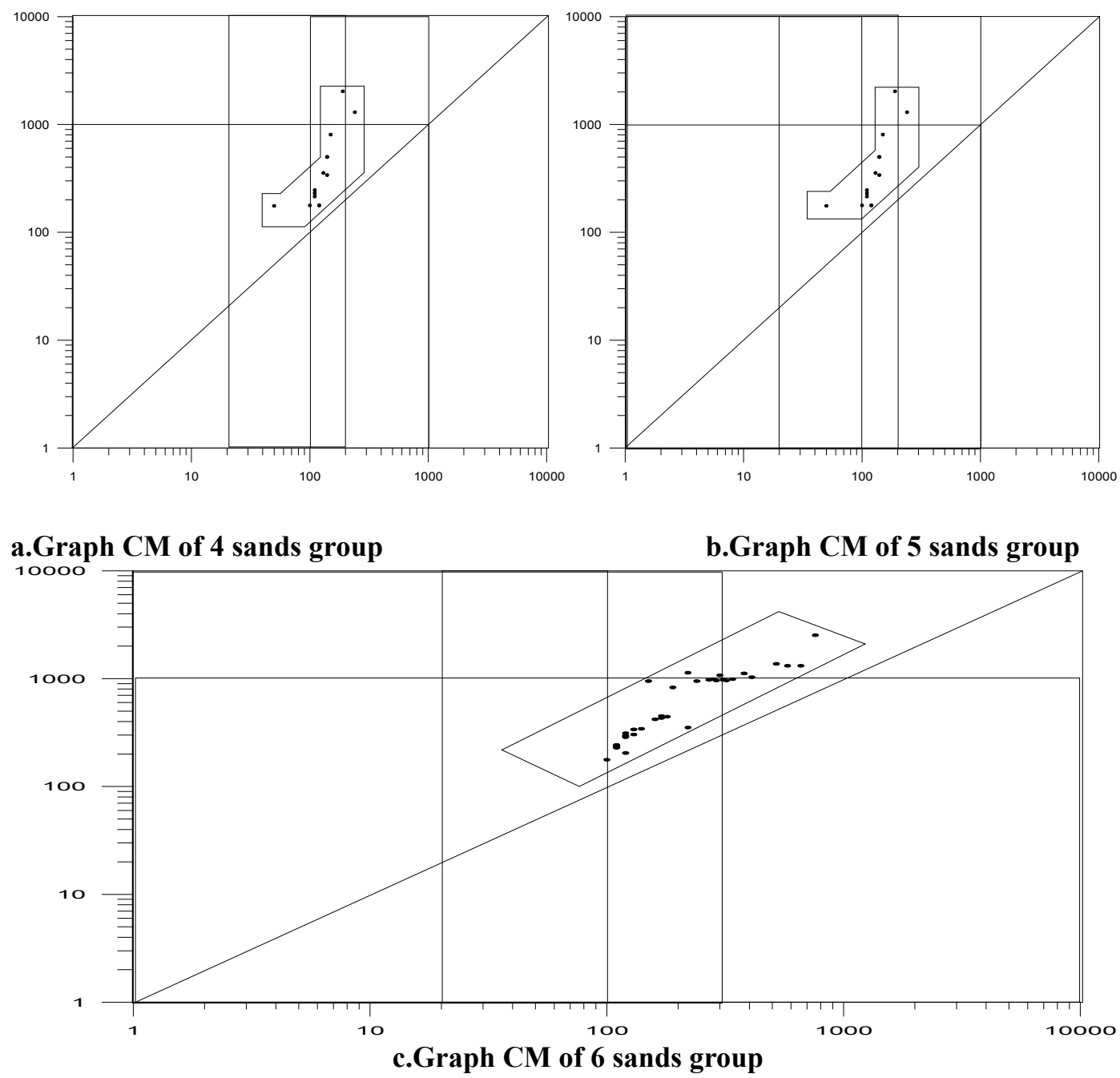

Graph4 The graph CM of 1-1-J53 4-6 sands group in well sands in two section

\section{The Depositional Facies Analysis}

The Electrofacies Analysis. Combined with the natural potential curve, resistance curve and microelectrode curve can well reflect the hydrodynamic condition, depositional sequence and structure when the sediments deposit very well, and they are an important means to study the depositional environment. I will tell some details about several main layers. It is shown in the following table 2-3.

$6^{3}$ curve character is shown as follows. The lower part shows the shape of natural potential curve box and funnel. The curve is smooth or has small teeth. The top part is gradient and the bottom part has a sudden change. With curve zigzag microelectrode has the characteristics of delta front. The upper part shows the shape of natural potential curve box. The curve is smooth. The top part is gradient and the bottom part is gradient. With curve zigzag microelectrode has the characteristics of delta front.

$6^{1}$ curve character is shown as follows. The natural potential curve shows the shape of box. The top part is smooth. The upper part has small teeth. The top part has a sudden change. The bottom part is gradient. With curve zigzag microelectrode has the characteristics of delta front. 
$5^{5}$ curve character is shown as follows. The lower part has the shape of box and funnel. The curve is smooth or has small teeth. With curve zigzag microelectrode has the characteristics of delta front. The upper part shows the shape of natural potential curve box. The curve is smooth or has small teeth. The top part has a sudden change. The bottom part has a sudden change or is gradient. With curve zigzag microelectrode has the characteristics of delta front.

$5^{4}$ curve character is shown as follows. The natural potential curve shows the shape of box, bell. The curve is smooth or has small teeth. The top part has a sudden change. The bottom part is gradient or has a sudden change. With curve zigzag microelectrode has the characteristics of delta front.

$4^{9}$ curve character is shown as follows. The natural potential curve shows the shape of box, bell. The curve is smooth. The top part is mostly gradient. The bottom part has a sudden change. With curve zigzag microelectrode has the depositional characteristics of the branch rivers.

$4^{7}$ curve character is shown as follows. The natural potential curve shows the shape of box and funnel. The curve is smooth or has small teeth. The top part has a sudden change. The bottom part is gradient or has a sudden change. With curve zigzag microelectrode has the depositional characteristics of estuary dam.

The Sand bodies' Geometric Shape. The sand bodies' geometric shape is the distributional condition of sediments in three-dimensional space, and it is an important information used to study the depositional environment. Different depositional environments can form different sand bodies' geometric shapes.

For fine oil reservoir description, we use Surfer software to draw the isopach map of sand bodies. And at the same time we will consider the water flow direction and provenance direction.

\section{The Division of Depositional Microfacies}

By the study of lithology, electrical property, paleontology and other facies, the division of depositional microfacies is a kind of method used for confirming depositional environment and the evolutionary law. Next I will analyze the microfacies of main small layers about 4-6 sands group of the second section in Shengyi area one by one.

The Microfacies Division of Six Sands Group. There are three main small layers in 6 sands group, namely 64, 63, 61. 64 has the depositional characteristics of reverse rhythm. There are two types of microfacies. In the plane it takes tuo15-2-1-1-740-1-1-71-1-0-8-1-1-7-1-2-103-1-3-10 well ligature as the border. In the west there is the testuary dam sediments. The thickness of sand bodies is between 7 and $17 \mathrm{~m}$. In the east there is the lateral margin sediments. Except the thickness of individual well areas is about $7 \mathrm{~m}$, the thickness of others is all less than $7 \mathrm{~m}$. The direction of water flow is from northwest to southeast. 63 small layer has the depositional characteristics of reverse rhythm. There are two types of microfacies. In the plane it takes 1-2-32- tuo $713-1-2-55-1-3-62-1-4-6$ well ligature as the border. In the west there are the testuary dam sediments. The thickness of sand bodies is between 1 and $11 \mathrm{~m}$. It takes 1-0-xie751-1-0-ning 78-1-1-102-1-3-142-1-3-ning 13 well ligature as the border. In the east there is the lateral margin sediments. The thickness of sand bodies is less than $11 \mathrm{~m}$. There are the testuary dam sediments between the two ligatures mentioned above. The thickness is more than $11 \mathrm{~m}$. The water flow direction is nearly the south north direction. 61 small layer has the depositional characteristics of reverse rhythm. There are two types of microfacies. In the plane it takes 1-1-31-1-jian53-1-1-72-1-2-10-1-2-113-1-3-11 well ligature as the border.In the west there is the core sediments of testuary dam. Except the thickness of individual well areas is less 
than $10 \mathrm{~m}$, the thickness of others is all $10-20 \mathrm{~m}$. In the east there is the lateral margin sediments of testuary dam. The thickness of sand bodies is less than $10 \mathrm{~m}$. The water flow direction is from northwest to southeast.

The Microfacies Division of Five Sands Group. Five sands group has two main small layers, namely 55, 54. 55 has the depositional characteristics of reverse rhythm. There are two types of microfacies. In the plane there are the lateral margin sediments of testuary dam within the scope of tuo15-2-1-1-73-1-2-92-1-3-9-1-3-11-1-2-131-1-1-9-1-0-742 well ligature trap.The thickness is less than $7 \mathrm{~m}$. And the rest area block is the core sediments of testuary dam. The water flow direction is from northwest to southeast. 54 has the depositional characteristics of positive rhythm. There are three types of microfacies. In the plane it takes 1-0-79-1-1-111-2-151 well ligature as the border. In northeast there are the floodplain sediments. The thickness is less than 2m. In 1-1-39、2-30、T713、1-2X38、TS1、1-1-46, 1-2-162 and 1-3-93、 $1-3-9 、 1-3-10$ well area there are tributary bay sediments. The thickness is less than $2 \mathrm{~m}$. And there are distributary river channels sediments in other area. The thickness is $2-6 \mathrm{~m}$. The water flow direction is from northwest to southeast.

The Microfacies Division of Four Sands Group. Four sands group has two main small layers, namely49, 47 . 49 has the depositional characteristics of positive rhythm. There are six types of microfacies. In the plane there are distributary river channels sediments within the scope of $1-1-35 、 1-2-32 、 1-2-590 、 1-2-54,1-3-32 、 1-3-52 、 1-3-63 、 1-3 N 6 、 1-4 N 5,1-4-67 、$ $1-3-7 、 1-3-78 、 1-2-711 、 1-2 N 8 、 1-2-102 、 1-1-83 、 1-1-88 、 1-2-123 、 1-2-144 、 1-2 X 136$ 、 $1-2-135,1-0-76 、 1-0-77 、 1-079$ well ligature trap. The thickness is between 3 and $10 \mathrm{~m}$. There are natural levee microfacies within the scope from 1-1-39、1-230、1-T713, 1-0-762、 1-0-761 、1-075、T41 well ligature to river channel sand bodies. The thickness is between $0.5 \mathrm{~m}$ and $4 \mathrm{~m}$. There are marsh microfacies in the west of 1-0X751 well area and 1-1-39、1-230、 1-T713 well ligature and in the south of 1-3-12、1-3-132、1-3-14 well ligature. 47 has the depositional characteristics of reverse rhythm. There are two types of microfacies. In the plane there are the lateral margin sediments of estuary dam in the east of 1-1-3-1-2-4211-2-73-1-2-71-1-2-92-1-3N9 well ligature border. The thickness is between $0.5 \mathrm{~m}$ and $4.5 \mathrm{~m}$. There are core sediments of estuary dam between 1-4-52-1-2-641-3N61-1-4-6 well ligature border and last ligature. The thickness is between $4.5 \mathrm{~m}$ and $10.5 \mathrm{~m}$. There are distal bar sediments in the southwest of this ligature. The thickness is between $2.5 \mathrm{~m}$ and $4.5 \mathrm{~m}$. The water flow direction is from northwest to southeast.

\section{References}

[1] J. Li, H.H. Wang, H.X. Zhao. The Structural Study of Chengdao Offshore Oil Field with the Micro amplitude. Institute of Xi 'an Petroleum University (Natural Science Edition), .2005, 20(1):: 23-25.

[2] Y. He, H. Yu, N.S. Wu. The Influence of Micro Structure on the Remaining Oil Distribution. Journal of Southwest Petroleum Institute, 2000, 22( 1) : 24-26.

[3] Yielding G, Freeman B, Needham D T. Quantitative Fault Sealprediction. AAPG Bulletin, $1997,81(6)$ : 8972917.

[4] Watt s K J . Theoretical Aspects of Cap Rock and Fault Seals for Single and Two Phase Hydrocarbon Columns . Marine and Pet roleum Geology, 1987, 31 (4):2742307. 
[5] Sorkhabi R, Suzuki U, Sato D. Structural Evaluation of Petroleum Sealing Capacity of Fault S[J] . SPE 59405, 2000. 129.

[6] Knipe R J . Faulting Processes and Fault Seal . Larsen R M , Brekke H, Larsen B T. St ructural and tectonic modeling and its application to pet roleum geology. Stavanger : Norwegion Pet roleum Society, 1992. 3252342. 